\title{
Correction to: Refractory Kawasaki Disease-A Challenge for the Pediatrician
}

\author{
Deepu Abraham $^{1} \cdot$ Sridhar Kalyanasundaram ${ }^{2} \cdot$ Kandamaran Krishnamurthy $^{3}$ (C)
}

Published online: 15 February 2021

(C) Springer Nature Switzerland AG 2021

\section{Correction to: SN Comprehensive Clinical Medicine https://doi.org/10.1007/s42399-021-00775-w}

Table 1 in the original article unfortunately needs to be changed.

The original article has been corrected.

Publisher's Note Springer Nature remains neutral with regard to jurisdictional claims in published maps and institutional affiliations.

The online version of the original article can be found at https://doi.org/ 10.1007/s42399-021-00775-w

Kandamaran Krishnamurthy

getdrkandy@yahoo.com

Deepu Abraham

drdeepuabraham@yahoo.com

Sridhar Kalyanasundaram

addensri@yahoo.com

1 Zulekha Hospital, Dubai, United Arab Emirates

2 Al Zahra Hospital, Dubai, United Arab Emirates

3 Queen Elizabeth Hospital, Bridgetown, Barbados 